\title{
A Conversation with Francisco J. Samaniego
}

\section{George G. Roussas and Debasis Bhattacharya}

\begin{abstract}
In a wide-ranging interview, Professor George G. Roussas of the University of California, Davis, and Professor Debasis Bhatacharya of VisvaBharati University, India, and a frequent visitor to UC Davis, engage Professor Francisco J. Samaniego in a discussion about his personal background, his education and the highlights of his professional career as a teacher and researcher.
\end{abstract}

Key words and phrases: Education, teaching and research, reliability theory, comparative statistical inference.

\section{FAMILY ROOTS, EARLY EDUCATION}

George: Frank, how about starting out by describing the roots of your family, and telling us something about your parents and your broader family?

Frank: My father's family emigrated from Durango, Mexico, to the United States in 1915, during a quite heated and dangerous part of the Mexican civil war. My grandfather was a dentist, trained in the U.S., and he had had a successful practice in Mexico. Due to illness, he was unable to practice dentistry when the family moved to the States. The two eldest sons, my father Mariano and his older brother Ramon, took on the responsibility for supporting the family. Both boys held several jobs simultaneously and worked hard to address the family's basic needs and to keep their siblings in school. My grandparents had hoped to move the family to California, and Ramon and Mariano soon moved to Los Angeles to try to establish a beachhead. The rest of the family moved to Los Angeles a year or two later.

One of Ramon's part-time jobs was as an "extra" on Hollywood movie sets. He soon was cast in leading roles in increasingly important films. Under the stage name, Ramon Novarro, my uncle had an enormously successful movie career, playing the lead in such celebrated films as "Ben Hur" and "Old Heidelberg" and playing an especially memorable role opposite Greta Garbo in "Mata Hari." Ramon's successful acting career was an essential element in assisting his family to move forward. With Ramon's support, my father (Mariano) returned to complete his high school education at the age of 26 , then studied at Loyola University, and later, got a degree in Dentistry

George G. Roussas is a Distinguished Professor Emeritus of Statistics, University of California, Davis, Davis, California 95616,USA (e-mail: ggroussas@ucdavis.edu).Debasis Bhattacharya is a Professor of Statistics, Visva-Bharati University, Santiniketan, India (e-mail:

debasis_us@yahoo.com). from UC San Francisco. Ramon's brothers Eduardo, Antonio and Angel earned college degrees in architecture, electrical engineering and civil engineering, respectively. My father decided to establish a dental practice in the gulf city of Tampico, Mexico. There, he met my mother, Carmen Azcarraga, one of nine children of Margarita Zavala Azcarraga and Francisco Azcarraga, the Chief Customs Officer of the port of Tampico. My parents married in 1941 and moved to Los Angeles late that year. My sister Margarita and I were born in LA in 1942 and 1944, respectively.

Debasis: Living in Southern California, we would assume you had most, if not all, of your basic education and college there. Is that so?

Frank: That's right, Debasis, with the exception of the year I spent obtaining a Master's degree at Ohio State University, I was educated at a variety of schools in Los Angeles. Sister Ann Michail, my 7th grade teacher at St. Brendan's Elementary School, solidly planted in me an appreciation for academic work. I attended Loyola High School, a Jesuit secondary school with a strong collegeprep curriculum which included four years of Latin, two years of Homeric Greek and plenty of math and science.

I stayed in Los Angeles for college, choosing to attend Loyola University along with 90 of my 200 classmates at Loyola High. Dr. Bert Wicker, chair of Loyola University's Mathematics Department and my Calculus instructor in freshman year, had a strong influence on my decision to change my major from Physics to Math. When, as an upper classman, I studied Advanced Calculus and Topology with Father Clarence Wallen, S. J.- an engaging lecturer with a true love of mathematics-I was totally hooked. In my senior year, I took a course in Statistics from Dr. Wicker, and it occurred to me then that Statistics might be the mathematical subfield in which I would specialize.

George: I know that you have a strong interest in the performing arts. Did your experiences with singing and acting begin when you were in high school? 


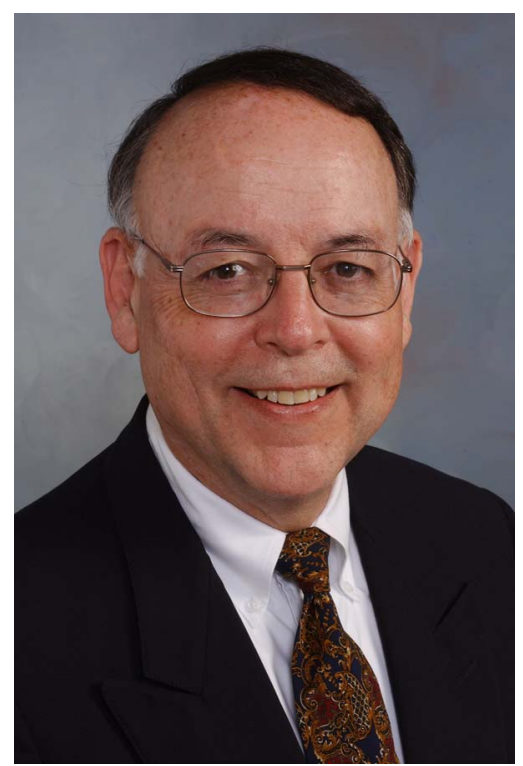

FIG. 1. F. J. Samaniego, circa 2004.

Frank: My experience on the stage is quite limited. I did sing in the Loyola High School Glee Club and, later, in the Loyola University Men's Chorus. Also, in the early '80s, I sang in the chorus in the Davis Comic Opera Company's productions of Gilbert and Sullivan's Rudigore and H. M. S. Pinafore. I was a member of the Davis Barbershop Chorus for several years, drawn in by the exhilarating harmonics. The only solo I ever performed was the jingle "With a Little Bit of Luck," accompanied by choreography from the musical "My Fair Lady," in an evening variety show at St. Ignatius Church in Sacramento in the 1990s. That went over so well that I decided to retire from the stage and rest on my laurels.

\section{RECOLLECTIONS ON YOUR GRADUATE YEARS}

Debasis: You started out your graduate work at Ohio State University, but you soon transferred to UCLA, where you completed it. How did this come about?

Frank: Yes, I went to Ohio State University for graduate work in the fall of 1966. I finished my Master's Degree at Ohio State in the summer of 1967, and decided to continue my education at UCLA. This decision was based mostly on what I knew of the reputation of UCLA statisticians Paul Hoel, Thomas Ferguson and Charles Stone, though I can't deny that the Southern California weather also influenced my decision to return. But I remember OSU fondly! The courses I took at Ohio State from Professors Arnold Ross, Louis Sucheston, Jagdish Rustagi and Ransom Whitney were very satisfying academically and laid a solid foundation for my further coursework in Mathematics and Statistics.

In my first year at UCLA, I took graduate courses in Real Analysis, Complex Analysis and Statistics. The Statistics course I took was taught by Tom Ferguson using his new graduate textbook Mathematical Statistics:
A Decision Theoretic Approach. During my second year at UCLA, I took the Ph.D. Written Qualifying exams in those three subjects and also in Abstract Algebra, in which I had taken very good courses at Loyola and at Ohio State. Some of my classmates at UCLA thought it bold of me to attempt the Ph.D. Exam in Algebra without having taken UCLA's version of the graduate course in the subject, but I felt I would be able to pass without additional coursework. As it happened, the Ph.D. written exam in algebra that year was right up my alley. The exam consisted of ten questions, with eight solutions asked for. I chose eight questions and was finished in 90 minutes. I checked my solutions and handed them in an hour early. A few weeks later, I was informed that I had written a perfect paper. A faculty member stopped me in the hall soon thereafter and asked me which of the UCLA algebraists I had studied with, as none of them recognized my name. I indicated that I learned abstract algebra from Professor Arnold Ross at Ohio State. I was also, vicariously, in the debt of Professor I. N. Herstein whose book "Topics in Algebra" was my bible at the time. I took another full year of coursework in graduate-level Mathematics and Statistics at UCLA. During that year, I approached Tom Ferguson about the possibility of writing a doctoral dissertation under his direction.

George: Give us a brief idea of what you studied in your doctoral dissertation.

Frank: The problem I addressed in my dissertation was an optimal design problem with a finite memory constraint (following the framework introduced by Stanford Professor Thomas Cover). In brief, I sought to identify the choice of randomization parameters governing transitions within a $k$-state machine that would produce the best possible estimator of a binomial parameter $p$ based on $n \gg k$ binary observations. While I enjoyed working on this and related problems, I did not see this as an area of research that I would pursue beyond the thesis. I did, however, publish four papers on this topic in the IEEE Transactions on Information Theory while moving on to other research areas.

George: In retrospect, all of us have reflected on our teachers, and singled out some of them for their special influence. What is your experience in this respect?

Frank: Sister Ann Michail, my 7th grade teacher at St. Brendan's Elementary School, was the first teacher to talk to me about the potential I had, in her view, for outstanding academic work. Her encouragement and support totally changed my trajectory. I began to take homework seriously and to earn A grades on exams. My 8th grade teacher, Sister Jean Dolores, reinforced the new direction I had taken and added new challenges. These two teachers were the perfect antidote for a student who was ready to study and learn but needed a spark to get the process started in earnest. I went on to four years at the Jesuit 


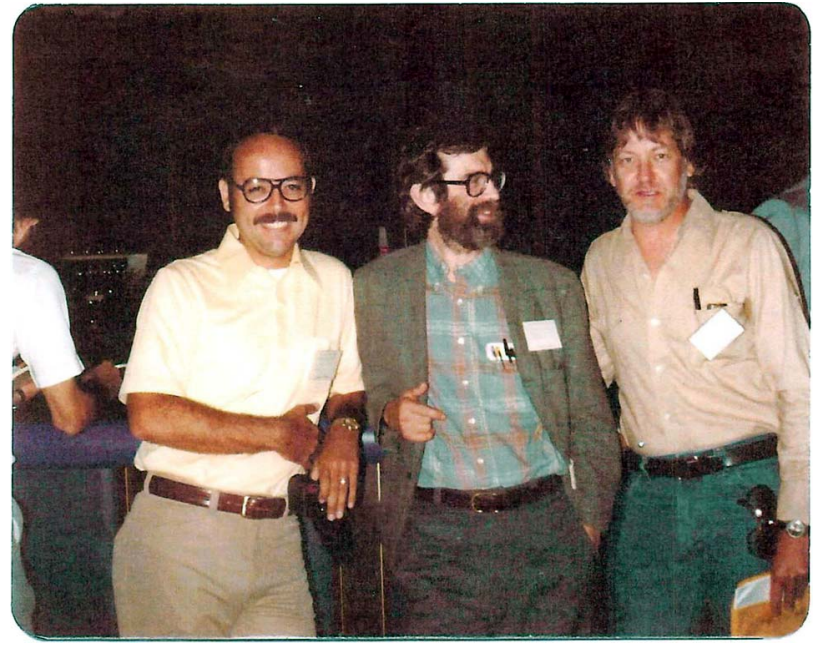

FIG. 2. Frank with Tom Ferguson and Don Ylvisaker at a statistical conference, circa 1980.

college-prep Loyola High School in Los Angeles, a highly competitive environment. It was at Loyola High School that I really learned how to study.

The teachers that had the greatest influence on me in college were mathematicians. Among these, Dr. Bert Wicker, whose year-long calculus class I took as a freshman, was largely responsible for changing my major from Physics to Mathematics. He was a fine teacher with an excellent feel for applications of mathematics. Father Clarence Wallen, S. J., who introduced me to abstract mathematics, was my instructor in two "rigorous" courses (Advanced Calculus and Topology) that I greatly enjoyed. Professor Arnold Ross, Fr. Wallen's mentor at Notre Dame, was then the chairman of the Mathematics Department at Ohio State University. That connection led me apply to OSU's Master of Science program in mathematics in the fall of 1966. Professor Ross taught a superb graduate course in abstract algebra. My decision to seek a Ph.D. in mathematics was largely due to how much I enjoyed that course. In the Fall of 1967, I enrolled in the Ph.D. program in Mathematics at UCLA, mostly because of what I knew about their Statistics faculty.

At UCLA, Tom Ferguson had the strongest influence on me, both as a superb teacher and as my dissertation advisor. He was generous with his time and his ideas, and he has been a model for me as a teacher and a researcher in my career as a university professor. Even now, when I think about a new research problem, I like to grab a clipboard, sit back in my chair and put my feet up on my desk. This relaxes me, and good ideas seem to follow. I learned the technique from Tom Ferguson! I also felt very well served by the courses I took from Professors Afifi, Jennrich and Liggett and by the numerous helpful conversations I had with Professor James McQueen from UCLA's Graduate School of Management.

Debasis: I know that you met your wife Mary when you were in college, and the two of you were married while you were in graduate school at UCLA. Can you fill in some details for us?

Frank: I met Mary O’Meara in 1966, when I was a senior at Loyola University and she was a sophomore at Mount Saint Mary's College. We had some mutual friends, and I would occasionally see her at parties or around my neighborhood, which was also hers. At one point that year, we went on a double date, but we didn't go out on a date of our own until much later. When I returned from a year at Ohio State after earning my Master's degree, I enrolled in the Ph.D. program at UCLA and worked part time as a high school teacher. Mary and I crossed paths again in 1968 at a rally for then-Senator Bobby Kennedy's presidential campaign. Soon thereafter, I took Mary out to dinner with some friends at Mario's Restaurant near UCLA. We began to see each other regularly and dated exclusively for almost two years. We were married on October 10, 1970, with Father Clarence Wallen, my former teacher at Loyola University, presiding. Mary has been a great partner to me, having the same values in terms of God, family, integrity and fun. She has been understanding about the demands of my work, and patient with me when I obsessed about my teaching or about some research project. She has always been supportive, but has also served me well as a balancing influence, reminding me, when necessary, about what's really important in life. I'm very much in her debt for that. Most importantly, she gave me two wonderful daughters, Monica and Elena, who have filled my life with pride and joy.

\section{POSTDOCTORAL FELLOWSHIP}

George: I understand that you had an interesting postdoctoral experience; would you tell us something about that?

Frank: I took a position as an NSF-sponsored Postdoctoral Fellow in the Statistics Department at Florida State in fall, 1971. Our first child, Monica Mary, was born in Tallahassee on February 5, 1972. This, of course, was the crowning achievement and most wonderful happening of the year. Though we were far from "home," we shared one of life's greatest experiences there, and marveled at every single thing that this beautiful little creature could do.

At Florida State, I had excellent interactions with a number of faculty. Teaching a graduate course jointly with Richard Savage was especially invigorating. I had illuminating conversations with senior faculty Richard Savage and Jayaram Sethuraman and with rising stars Myles Hollander and Bob Serfling. I shared an office with Ismail Shimi, whose thoughts and advice about careers in academia made a lasting impression on me. Excellence and balance as a university teacher/researcher were recurring themes. Later in his career, Ismail headed the grant 


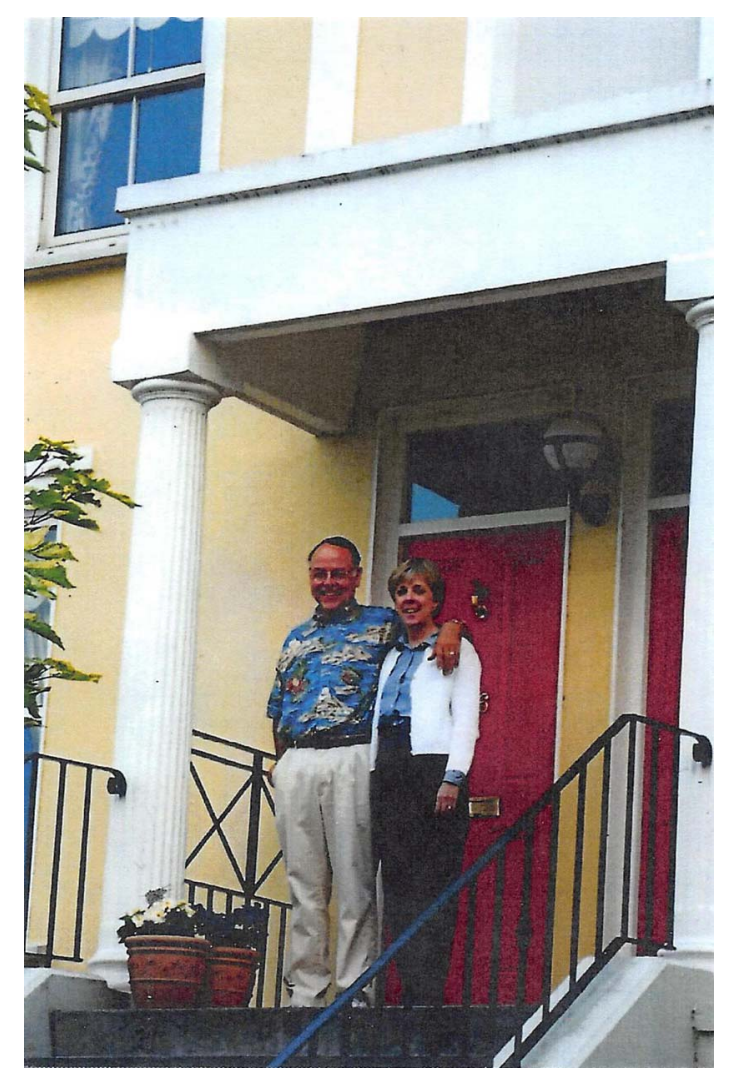

FIG. 3. Frank and Mary at their residence in Dublin, Ireland, while on sabbatical leave from UC Davis in the Spring 2001.

program in Statistics at the Air Force Office of Scientific Research.

I was introduced to Statistical Reliability Theory by the master himself. I attended Frank Proschan's Reliability Seminar at Florida State and read many of his papers. This exposure to Reliability Theory had a huge impact on my research career. This statistical subfield is primarily motivated by real life problems and interesting industrial applications. It has solid theoretical foundations and often focuses on statistical analyses that are authentically useful in engineering applications. Research in Reliability Theory offers, simultaneously, opportunities for novel and interesting statistical modeling and for fresh and useful statistical theory. I drew a great deal of inspiration from both FSU's Frank Proschan and from Berkeley's Dick Barlow, and I've always taught the upper-division Reliability course at UC Davis using their classic textbook Statistical Theory and Life Testing. One of the fondest memories at UC Davis was Proschan's two-week visit as a Regent's Lecturer in the late 1980s. During that visit, I had the pleasure of hosting the Mount Rushmore of Reliability — Richard Barlow, James Esary, Albert Marshall and Frank Proschan - at my home for dinner.

\section{YOUR MOVE TO THE UNIVERSITY OF CALIFORNIA, DAVIS}

Debasis: Please tell us about your return to California and your settling in Davis with your family. We should not commit the cardinal error by not asking you to say something about your immediate family.

Frank: Early during my year at Florida State, I noticed that the Mathematics Department at UC Davis was seeking to fill an opening for an Assistant Professor with a specialization in Statistics. The thought of returning to California greatly appealed to us, so I applied for the position. I interviewed for several positions around the country that year, but I was hoping that things would work out at UC Davis, and they did. I was offered an appointment at Davis, filling the position vacated by the retirement of Professor George Baker. I accepted the offer, and we moved to Davis in August, 1972.

The small Samaniego clan settled comfortably in Davis, renting at first, and buying our first home in the spring of 1973. Our second daughter, Elena Carmen, was born in Sacramento on August 18, 1974. Both girls attended St. James Elementary School in Davis, with Monica graduating in 1986. We moved to Sacramento in December, 1986, the move largely due to the fact that Monica was already attending St. Francis High School in Sacramento, from which Monica graduated in 1990. Elena joined the 7th grade class at St. Ignatius Elementary School in Sacramento in 1986, graduating in 1988, and she graduated from Loretto High School in 1992. Both Monica and Elena attended Santa Clara University, graduating in 1994 and 1996, having majored in History and English, respectively.

Both of my daughters pursued teaching careers after college. Monica got her credential in elementary education and taught a 2nd grade class. She married Karl Edward (Keb) Byers in 2000, and they have given us two wonderful grandsons, Jack (16) and Will (12). Monica "retired" from teaching just before Jack was born, but hopes to return to the classroom in a few years. The Byers family lives in Lafayette, CA, from which Keb has been commuting via BART to work in San Francisco as a Vice President at Wells Fargo Bank. Keb retired from Wells Fargo in the summer of 2018 after 30 years of service at the bank. My other daughter, Elena, teaches English at Laguna Creek High School in Elk Grove, and is presently in her 12th year on the faculty there. We feel blessed to have both of our daughters close by, as we are able to enjoy virtually all holidays and special events together.

George: Could you mention some of the highlights of your early years at UC Davis?

Frank: I joined the Mathematics Department at UC Davis in July 1972. The math department had long been the home for a small group of statisticians. During my early years at Davis, my research focus changed. The first 
problem area that I explored after joining UC Davis involved inference based on discrete signals observed in the presence of additive noise. This research started somewhat accidentally. It began the day I noticed that the Poisson distribution satisfies a certain equation involving derivatives of the distribution function with respect to the mean parameter. Naturally, I wondered if the class of Poisson distributions was the unique family of discrete probability distributions that satisfied these differential equations. I discovered that it was not, but that the complete solution was a very interesting class-the family of convoluted Poisson distributions (i.e., the distributions of Poisson signals in additive noise). My research on that topic was published in JASA in 1976. That paper spawned a number of related studies and led, in 1981, to a much more general Annals of Statistics paper (joint with Master's degree student Gail Gong) entitled "Pseudo Maximum Likelihood Estimation: Theory and Applications." In the latter paper, we developed the asymptotic theory for estimators which maximize the "pseudo likelihood," that is, the likelihood function depending on an unknown target parameter, where the model's nuisance parameters are replaced by data-based estimates.

Another area that I had the chance to explore early on began with some discussions that I had with faculty and graduate students from the Civil Engineering Department at UC Davis. The work had to do with design questions involving "activated sludge processes," with the goal of identifying process designs leading to near-optimal operational reliability. Three scholarly papers resulted from this collaboration. I also published a theoretical paper on estimating the value of an auctioned item from a sequence of observed bids and a paper on Bayesian estimation when sampling from a Pearson Type III distribution. I was promoted to the rank of Associate Professor, with tenure, in 1977.

\section{THE DEVELOPMENT OF AN INDEPENDENT UNIT IN STATISTICS AT DAVIS}

Debasis: In 1979, an independent statistics unit was established on campus. I know that you played an instrumental role in that development. Would you summarize the relevant events as they happened?

Frank: Chancellor James Meyer established a campuswide committee in 1976-1977 charged with studying the possibility of establishing a separate academic unit in Statistics at UC Davis. In its final report, the committee recommended the establishment of an intercollege unit which could accommodate statistics faculty presently serving in several schools and colleges and which would be provided the resources to recruit additional faculty with the view of serving the campus's needs for statistical instruction, consultation and collaboration. The envisioned unit would serve as the home department for both theoretical and applied statisticians. The Chancellor provided an FTE position to the Department of Mathematics to be filled by a senior-level statistician who could take the lead in this endeavor. Dr. John van Ryzin, Professor of Statistics at the University of Wisconsin, Madison, and former chair of its Statistics Department, joined UC Davis's math department in the fall of 1977 and accepted the charge of working on the development of an independent academic program in Statistics. John worked toward this goal in academic year 1977-1978, and some serious progress was made. However, with considerable turmoil in his personal life, he found it difficult to devote himself fully to the task of creating a new academic program in Statistics. He left Davis in June 1978, taking a position with the Rand Corporation in Santa Monica.

John's departure from Davis was sudden and unexpected, and there was a bit of uncertainty about possible next steps. The day after John's departure, I met with Leon Mayhew, the Vice Chancellor for Academic Affairs at Davis, and asked him a simple question: "Are we going ahead with our plan for an independent Statistics unit?" Without any hesitation, Leon said "Absolutely." He asked me to take the lead in that effort. He appointed me to serve as a Faculty Assistant in his office and asked me to oversee the transition to a separate Statistics unit from there. I started writing almost immediately, as there was still a good deal of paperwork needed for the establishment of new Statistics units at UC Davis. The University's Board of Regents would need to approve formal proposals for the establishment of a new academic unit, a new graduate program and a new consulting unit in Statistics, to be named The Statistical Laboratory. Over several months, I submitted formal proposals for the establishment of an Intercollege Division of Statistics, a Graduate Group in Statistics and a Statistical Laboratory to UC Davis's Office of Academic Affairs for review and consideration by relevant Academic Senate committees.

The Intercollege Division of Statistics was approved in the fall of 1978. I served as its first and only faculty member in the Winter and Spring Quarters of 1979, also serving as Acting Associate Dean for Statistics. I immediately began work on the transfer of five UC Davis faculty members from their appointments in other units to an appointment in the Division of Statistics. I also chaired the Search Committee for three senior faculty positions in the Division. These searches led to the appointment of Julius Blum, then Professor of Mathematics at the University of Wisconsin, Milwaukee, as Professor of Statistics and Associate Dean of the Division, effective on July 1, 1979. Dr. P. K. Bhattacharya and Dr. Robert Shumway also joined the Division of Statistics as Full Professors, with tenure. Dr. Alvin Wiggins, then Associate Professor of Veterinary Medicine, was appointed Associate Professor of Statistics 
and also Director of the Statistical Laboratory, on July 1, 1979. The founding faculty of the Intercollege Division of Statistics consisted of Professor and Chair Julius Blum, Professors Bhattacharya and Shumway, Associate Professors Samaniego and Wiggins and Assistant Professors Fenech, Johnson, Matloff and Utts. The unit remained more or less stable until 1985 when George was hired as a replacement of the diseased Julius Blum.

\section{RESEARCH INTERESTS}

Debasis: Would you outline for us briefly your research interests, and single out what you feel are your most significant contributions? Please, elaborate on the notion of "system signature," with which your name has been identified.

Frank: My first sustained research effort beyond the ideas studied in my thesis (on statistical inference under a finite memory constraint) involved modeling and inference for discrete signals in additive noise. My interest in such models began with a mathematical coincidence, my discovery that the distribution functions of certain convolution models arose as the precise family of solutions to particular differential equations. The study of such problems eventually led me to focus on what I called "pseudo maximum likelihood estimation", an approach that uses likelihood methods for estimating a target parameter after replacing nuisance parameters with simple plug-in estimators.

I've also been interested, over the years, in methods of treating data obtained by nonstandard sampling methods. Two examples would be "nomination sampling," which consists of a sample of observed maxima (the observations being the largest values in each of several independent subsamples of varying sizes, for example, high school students' best scores in several sittings for the Scholastic Aptitude Test), and "ranked set sampling," which consists of independently observed order statistics $\left\{X_{k, n}\right\}$, where both the order $k$ and the sample size $n$ can vary from observation to observation.

In the 1990s, I became interested in "comparative statistical inference," trying to answer, analytically, the largely unexplored question of when and why a Bayes estimator of an unknown parameter might have better (or worse) performance than "the best frequentist estimator" of that parameter. In the 1994 JASA paper, graduate student Dana Reneau and I solved a version of what we called "the threshold problem," the problem of finding the dividing line between Bayes estimators that were superior to the best frequentist estimator and Bayes estimators that were not. The framework in which our initial results were obtained involved squared error loss, data drawn from exponential families and prior distributions from conjugate families. The results provided a useful performance-based guidepost when deciding when to use a Bayesian or frequentist approach in estimating an unknown parameter. That paper, and related subsequent work (including work with you, Debasis) led to my 2010 Springer monograph on comparative inference. Along the way, a variety of new research topics arose quite naturally. Examples include the notion of Bayesian self-consistency and the Bayesian treatment of nonidentifiable models.

One of my constant research interests over the years is modeling and inference in Reliability. The postdoctoral year I spent at Florida State introduced me to a variety of open problems in reliability. Frank Proschan, a major figure in reliability theory (indeed, one of the founding fathers of the area) had a major influence on my research trajectory. I'll briefly mention the main topics in reliability that I and my collaborators have studied: estimation of a system's reliability function when it is known to belong to a given nonparametric class; inference based on a sequence of record-breaking observations; estimating reliability from a "nomination sample" or a "ranked-set sample"; and inference for the reliability of a system subject to imperfect repair. A more complete list of papers I've written on topics in reliability appears in the bibliography. A few highlights, grouped into several categories within reliability are mentioned below.

One area in which I have long been interested involves nonparametric models in reliability and the associated inference given data from such models. Examples of such work include my 1984 paper on estimating a survival function known to belong to the "New Better than Used" class and papers in 2000 and 2002 on estimating distribution functions subject to a "uniform stochastic ordering" or a "stochastic precedence" constraint. Another area that has interested me is inference about system reliability based on nonstandard data, that is, under sampling schemes other than simple random sampling. Examples of that work include papers in 1986 and 1988 on nonparametric inference based on record-breaking observations and papers in 1993 and 1994 on estimating distribution functions based on ranked-set sampling or nomination sampling.

A line of research that I have especially enjoyed is the trajectory that is related to the idea of "system signatures." The signature concept itself is very simple. Given an $n$ component system with i.i.d. component lifetimes, system's signature is just the $n$-dimensional probability vector $s$ whose $i$ th component is $s_{i}=P\left(T=X_{i: n}\right)$, where $T$ is the lifetime of the system and $X_{i: n}$ is the failure time of the $i$ th component to fail. There are two theoretical properties that underscore the utility of the signature vector as a good measure of the quality of a system's performance. One is a representation theorem which shows that a system whose components have i.i.d. lifetimes with distribution $F$ has a probability distribution which depends only on $F$ and the signature vector $\boldsymbol{s}$. A second 


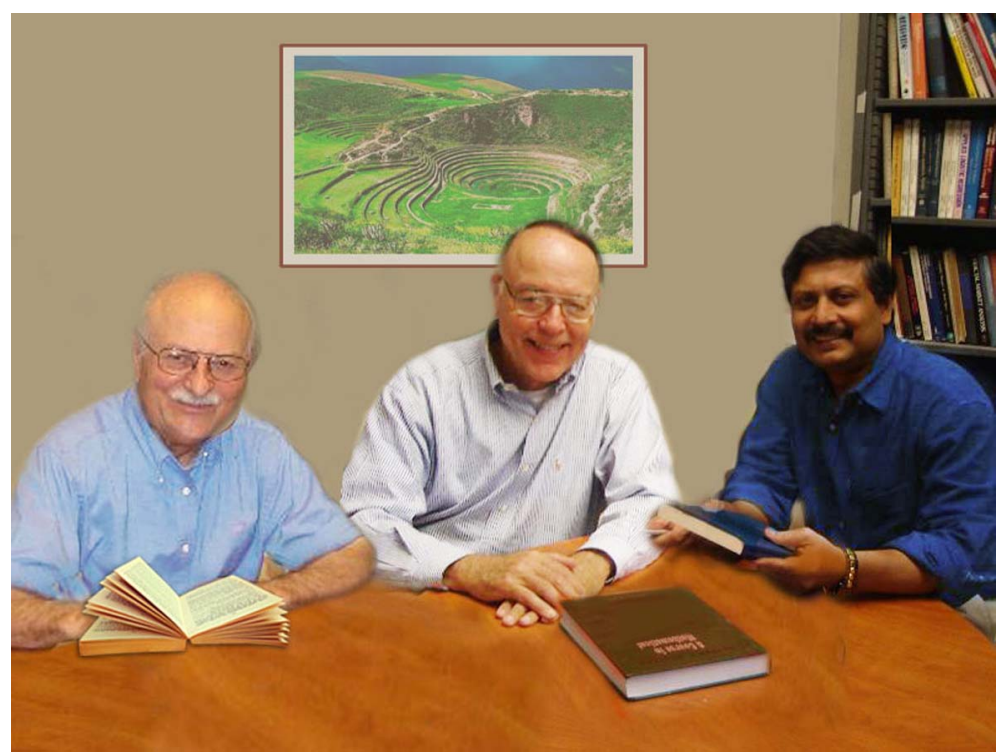

FIG. 4. Frank, Debasis and George in George's office at the UC Davis.

result states that the quality of the system depends directly on the quality of the system's signature. For example, given two systems with i.i.d. component lifetimes, it can be proven that stochastic ordering between the twosystem signatures will imply stochastic ordering between the two-system lifetimes. The notion of "system signatures" was introduced in my 1985 IEEE Transactions on Reliability paper.

"On the Closure of the IFR Class under the Formation of Coherent Systems," IEEE Transactions on Reliability, Vol. R-34 (1985), 69-72.

About a dozen years later, Hari Mukerjee, Subhash Kochar and I we found it possible to expand upon the signature idea, leading to the 1999 paper in Naval Research Logistics that helped to establish the broad utility of system signatures.

My early work on system signatures is presented in a unified way in my 2007 Springer monograph System Signatures and their Applications in Engineering Reliability. I have been very pleased to see that the applicability of system signatures in the field of Reliability theory and has been advanced by other researchers and continues to be explored.

George: Would you, please, mention briefly your Ph.D. students and their research topics?

Frank: My first doctoral student was Russell Boyle, who focused on a problem in nonparametric estimation in Reliability Theory, but we also wrote joint research papers on four other problems: parameter estimation for a discrete shock model, statistical inference based on multivariate binary data with positive dependence, the characterization of discrete signals in additive noise and nonparametric estimation based on a nomination sample.

Lyn Whitaker, whose thesis work was about statistical inference based on a sample of "record-breaking" obser- vations, was my second doctoral student. Lyn and I published work on several other problems together. Perhaps the best known paper among them is our 1989 JASA paper entitled "On Estimating the Reliability of Systems Subject to Imperfect Repair."

My next doctoral student was Dana Reneau, who studied a collection of nonparametric estimation problems for various subclasses of the "New Better than Used" family of nonparametric distributions. Our paper entitled "Estimating a Survival Curve When New is Better than Used of a Specified Age," was published in the JASA in 1990. A companion paper was published in Naval Research Logistics the following year. Another joint work with him entitled "Towards a Reconciliation of the Bayes and Frequentist Approach to Estimation" was published in JASA in 1994.

Paul Kvam, who came to us with a Master's degree from the University of Florida, moved quickly in the doctoral program at UC Davis. His research problems were focused on the area of Reliability Theory. We first explored nonparametric maximum likelihood estimation based on ranked set samples, and wrote a paper on the estimation of system reliability using that approach. In another paper, we showed that empirical averages based on ranked set samples, and in another paper, we showed that empirical averages could be inadmissible as estimators of a population mean.

My next doctoral student was Andy Neath, whose thesis was focused on Bayes and empirical Bayes procedures in a number of different contexts, including problems in multiparameter estimation, inference problems in a "competing risks" framework and Bayesian estimation of the parameters of nonidentifiable models. One particularly memorable paper of ours is the 1996 JASA paper. 


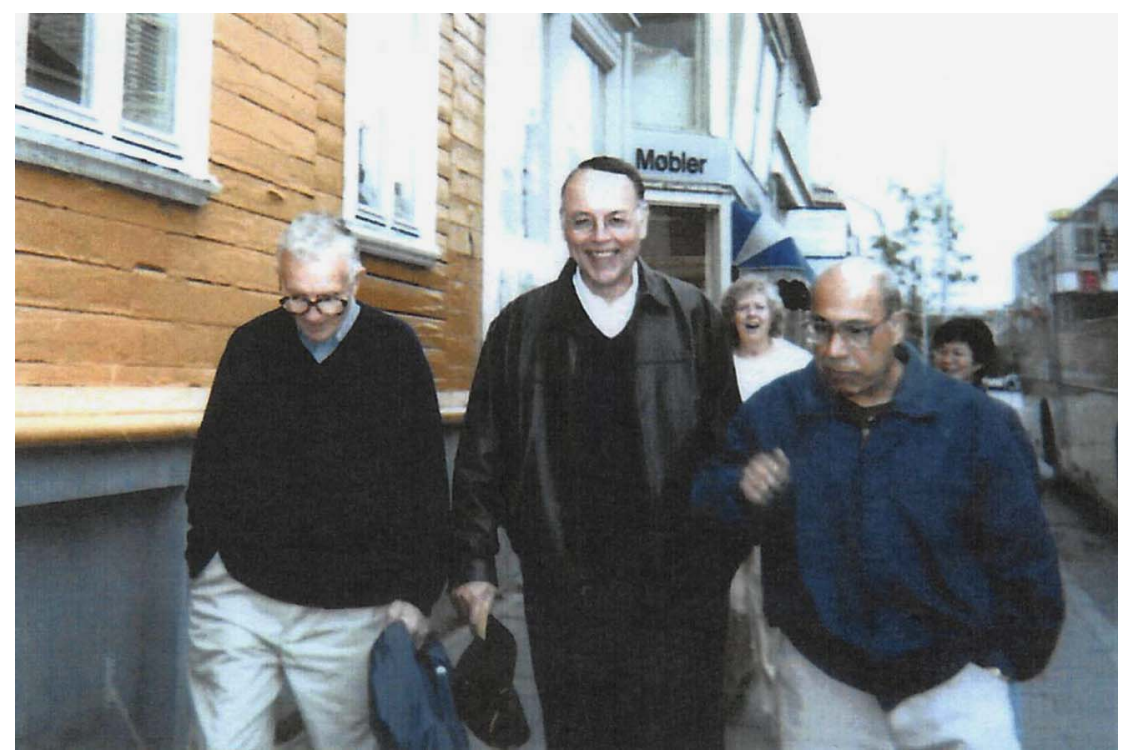

FIG. 5. Frank with Dick Barlow and Nozer Singpurwalla at a "Mathematical Methods in Reiability (MMR)" Conference in Trondheim in 2002.

Eric Vestrup may be the most mathematically inclined among my doctoral students. His dissertation focused on the comparison of Bayes and frequentist estimators in a variety of contexts. During his time as a graduate student, Eric and I also published two papers on Network Reliability, including a very satisfying piece in which the relationship between the vector of "dominations" (i.e., the coefficients of a network's reliability polynomial) and the network's signature vector was explicitly identified.

My next doctoral student was Michael Dugas, whose doctoral dissertation was focused on statistical problems to the field of "Reliability Economics." Our first investigation led to the characterization of the optimal system design satisfying both reliability and economic constraints. Mike and I also wrote a pair of papers together which developed signature-based representations of system lifetimes and failure rates and signature-based results on the reliability of competing systems.

My last doctoral student was Yin (Golden) Jin, whose doctoral dissertation was co-directed by Peter Hall. Peter held a joint appointment at UC Davis as Distinguished Professor of Statistics. He was in residence at Davis every spring quarter.The arrangement proved to be totally workable. Golden's dissertation proceeded at a standard pace. Two of its trajectories were published in Statistica Sinica under the titles "Nonparametric Estimation of Component Reliability Based on Lifetime Data from Systems of Varying Design" (Hall, Jin and Samaniego) and "Estimating Component Characteristics Based on Lifetime Data from a System of Unknown Design" (Jin, Hall, Jiang and Samaniego). Jin now works in the Statistics Group at Facebook.

George: Please tell us briefly about any other research projects that you see as especially memorable.
Frank: I will mention several papers that I especially enjoyed, mostly for the dynamic collaborative effort involved, but some for end product itself, which advanced the field and has had some staying power.

The first one I'll mention was my 1981 Annals of Statistics paper with Gail Gong on "Pseudo Maximum Likelihood Estimation." The paper derived the asymptotic distribution of an estimator obtained as the solution of a "fake" likelihood equation, that is, an equation with all parameters, save the "target parameter," replaced by "root- $n$ consistent" estimators based on the available data. Our result obtained the exact asymptotics, showing that, except in extraordinary circumstances, the asymptotic variance of the pseudo MLE is, as one might expect, larger. As "plug in" estimators are often used in practice, our results on their asymptotic behavior have been widely cited.

My 1985 paper "On the Closure of the IFR Class under the Formation of Coherent Systems," published in the IEEE Transactions on Reliability, turned out to be an important reference in the area of Reliability Theory. In that paper, I defined what later came to be called the "signature" $s$ of a coherent system with $n$ components. The signature of a system with $n$ components with i.i.d. lifetimes is an $n$-dimensional vector $\boldsymbol{s}$ whose $i$ th element is the probability $s_{i}=P\left(T=X_{i: n}\right)$, where $T$ is the system's lifetime and $\mathrm{X}_{i: n}$ is the failure time of the $i$ th component to fail (i.e., the $i$ th order statistic in the sample of $n$ failure times).

In a 1999 Naval Research Logistics paper entitled "On the Signature of a Coherent System and its Application to Comparisons among Systems," (joint with S. Kochar and H. Mukerjee), my co-authors and I proved a representation theorem that showed that, for a system in i.i.d. components with distribution $F$, the distribution of the system's lifetime $T$ depends only on the system signature $\boldsymbol{s}$ 
and the common component distribution $F$, with the relationship given explicitly in the paper. It was also shown that the ordering of two signature vectors implies the ordering of the two system lifetimes. This property strongly suggests that the signature vector is the "appropriate summary measure" of a system's design.

The fourth paper, published in JASA in 1994, was joint work with Dana Reneau. That paper presented a theorem which gave explicit conditions under which a Bayes estimator of an unknown scalar parameter, relative to squared error loss, was superior to (i.e., had a smaller Bayes risk relative the true, albeit unknown, prior distribution on the unknown parameter) the best frequentist estimator. My 2010 Springer monograph entitled "A Comparison of the Bayesian and Frequentist Approaches to Estimation" presents a comprehensive treatment of comparative inference, and treats, in particular, issues such as the notion of Bayesian self-consistency, estimation for multivariate normal models, estimation under asymmetric loss and the Bayesian treatment of nonidentifiable models.

Three other papers which, I believe, made important conceptual contributions to Reliability theory and practice treated three quite different problems. In a 2002 JASA paper, the feasibility of treating inference problems under a new and interesting constraint referred to as "stochastic precedence (SP)" was demonstrated. In a $2007 N R L$ paper, the optimal system design was explicitly identified under a criterion function which depended on both the performance and the cost of an engineered system. In a $2014 C o S-T \& M$ paper, it was demonstrated that, using the SP metric for comparing engineered systems, one could identify a system of a fixed size that was universally better than all others. Such results-obtained with co-authors-also appeared in JASA 2002, and NRL 2007.

Debasis: In a series of papers, you studied extensively the comparative performance of the frequentist and the Bayesian approach to statistical inference, culminating in a monograph. Would you elaborate on this subject?

Frank: In brief, I would say that the question that has intrigued me is simply: When is one approach better (or worse) than the other? Or, alternatively, when does the Bayesian statistician have the advantage? Intuitively, the answer to the question must certainly be, "When the Bayesian has 'good' prior information." But making that answer precise was challenging. I sought to characterize the class of prior distributions that led to "better answers" than the "best" frequentist answer.

The 1994 JASA paper-joint with Dana Reneauprovided a performance-based solution to this problem when estimating a scalar parameter under squared error loss. In that paper, the boundary which separates superior from inferior priors (in the class considered) was explicitly displayed. A striking feature of the class of priors for which the Bayes estimator outperforms the best frequentist estimator was that the class was much larger than standard intuition would predict. The Bayes rule could be superior to the frequentist rule even when the prior distribution seemed to be quite weak. The comparison I pursued between the Bayesian and frequentist approaches to estimation eschewed the usual philosophical posturing one sees in the literature; instead, I proposed a performancebased criterion for deciding between the two approaches.

My 2010 Springer monograph comparing Bayesian and frequentist estimation begins with a review of two approaches and then defines the "threshold problem," that is, the problem of determining the boundary, in the space of prior distributions under consideration, which separates "good" and "bad" Bayes estimators. It gives quite complete answers for estimating scalar parameters under squared error loss, and it treats generalizations such as parameter estimation in multivariate normal models and for nonidentifiable models. It also treats estimation relative to an asymmetric loss criterion. Along the way, I discuss the interesting notion of prior "self-consistency" and deal with the Bayesian treatments of nonidentifiability and of data from "related" experiments. In the book's concluding chapter, which is aptly entitled "Fatherly Advice," I offer the following summary comments about deciding between the Bayesian and frequentist approaches to a given problem: In problems of statistical estimation, a Bayesian will tend to do well (and better than the frequentist) unless he/she is both misguided and stubborn. A misguided Bayesian has a "poor" prior guess at the parameter, and a stubborn Bayesian puts a good deal of weight on his/her guess. The technical results in the monograph give ample support to the claim that Bayesians can still be successful with one of these two deficiencies, but they will tend to do quite poorly when they have both. Of course, when they have neither of these deficiencies, Bayes estimators are hard to beat.

\section{TEACHING, EDITORIAL WORK, OTHER PROFESSIONAL ACTIVITIES}

Debasis: We know that you have been an excellent teacher, honored on this account at least twice. Also, you have offered many services at the UC Davis campus, including serving in upper-level administrative positions. Could you give a brief summary of these events and activities?

Frank: My approach to teaching was pretty basic. Good preparation was essential. I always had carefully prepared notes on what I hoped to accomplish in a given lecture. My number one goal was clarity. I also wanted my lectures to be logically organized, making them easier for students to digest and remember. Getting students to think along with me was also a goal. I wanted them to help me make a particular argument in class rather than just to 


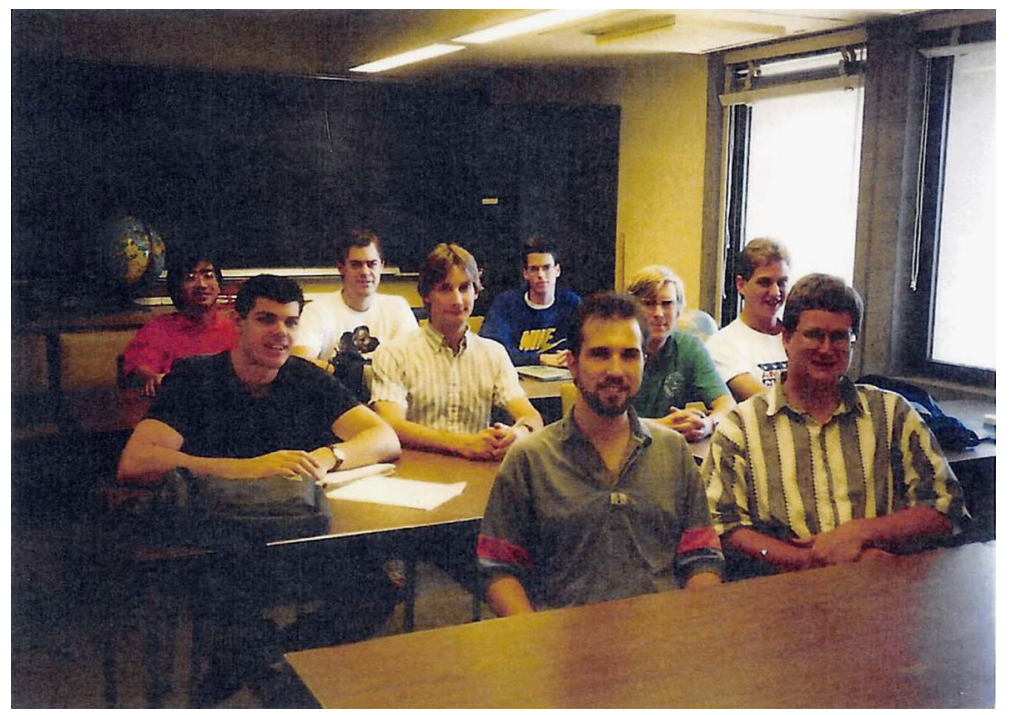

FIG. 6. Frank's Reliability Theory class in the early 1990s.

write down what I said or I wrote on the board. I am a fan of Socratic dialogue, and though I tended to give traditional lectures, I would often seek help from the students in identifying the next logical step in an argument.

I received the Academic Senate's Distinguished Teaching Award at UC Davis in 2002. At that point, I had been at Davis for 30 years, and I certainly didn't expect the recognition. But I was very pleased and honored by the award, mostly because my own teaching style was really an amalgam of the styles of a good number of outstanding teachers I had as a student. In accepting the award, I had the opportunity to recognize the special influence they had had on me. Two years later, it was my good fortune to receive the UC Davis Prize for Undergraduate Teaching and Scholarly Achievement. The Davis Prize is awarded to a single faculty member each year for notable career accomplishments in both teaching and research. This award meant a great deal to me because it served to validate the decision I made early on to try to dedicate myself equally to both teaching and research, aiming to be the best I could be at each. Receiving the Davis Prize signaled to me that my academic aspirations had largely been realized. For me, it was a moment filled with both gratitude and satisfaction. As if this wasn't enough, I also received a couple of years later, a lovely recognition from the Associated Students of UC Davis, an award for outstanding teaching in the Mathematical and Physical Sciences at Davis. This award, being directly from students rather than from faculty colleagues or from the university administration, meant a lot to me. The faculty is there to serve the students, to guide and inspire them and to help them achieve their potential and find their true calling. An acknowledgment from those you serve is very special.

My career as a university administrator was brief. I served as Assistant Vice Chancellor for Academic Affairs for five years in the 1980s. My work there was mostly involved with overseeing, together with Vice Chancellor Robert Cello, the academic personnel process, including faculty appointments, academic advancement, tenure decisions, faculty development and related programs. The administrative work was extremely time consuming, and I retained a $20 \%$ time appointment in my department while working what, in reality, amounted to more than a full time job in administration. But I learned a good deal from my time in university administration, and I definitely enjoyed the satisfaction of helping faculty who sought assistance in solving problems that were interfering with their ability to do their best work. I particularly enjoyed my interactions with campus administrators, especially Chancellor Jim Meyer, Vice Chancellors Bob Cello and Larry Vanderhoef and Deans Larry Andrews, Leon Mayhew, Charley Hess and Mo Ghausi. One initiative in which I played a major role was an affirmative action program which sought to recruit senior-level, distinguished minority and women scholars to Davis. The impact of these highly visible recruitments was notable, as it underscored the campus's simultaneous commitment to both diversity and academic excellence by investing in the extraordinary models of excellence who joined the faculty's senior ranks during this period. I returned to full-time faculty service in July, 1988, serving as a Professor of Statistics until my retirement in 2013.

George: At the professional level at large, you have participated in numerous national and international meetings, served on various committees, did editorial work, and most importantly, you served as the Editor of the Journal of the American Statistical Association. Would you elaborate on these activities?

Frank: Having joined a mathematics department after my doctoral studies, I was especially driven to participate in Statistical meetings and conferences in the US and beyond. This was motivated, in part, by the need I felt to stay 


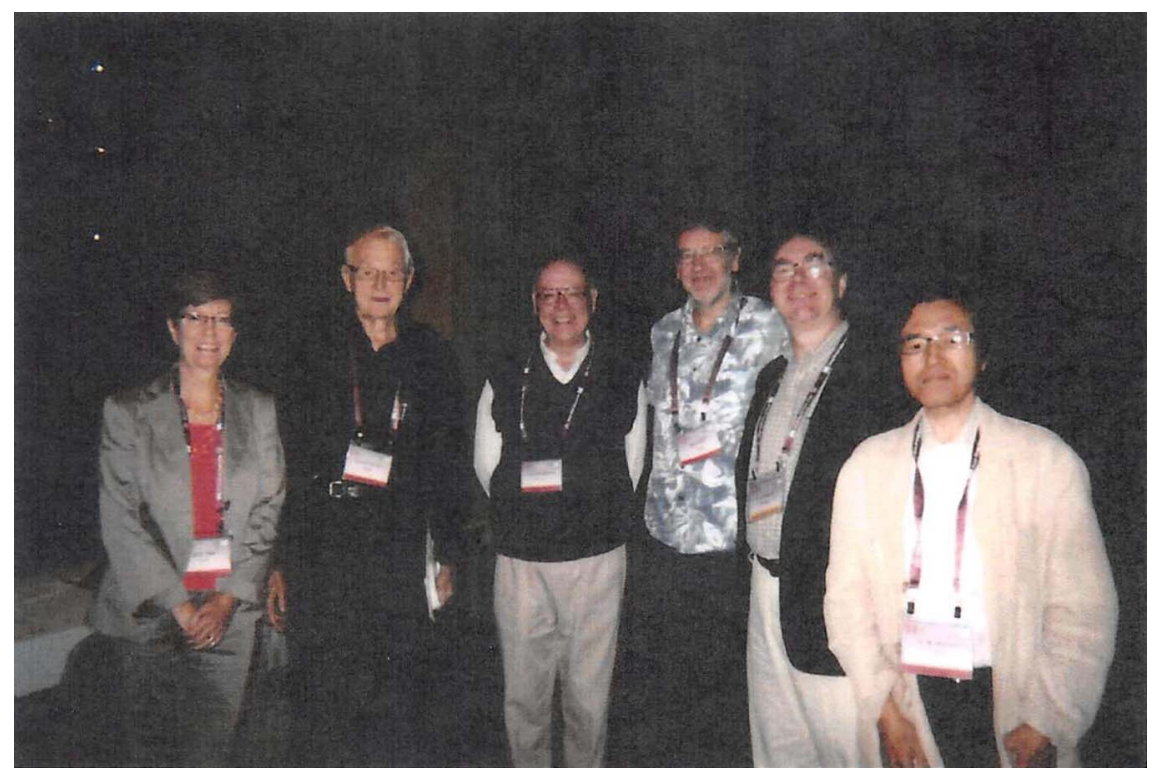

FIG. 7. Frank with Professors Reid, Fraser, Kjort, Banks and Iwasaki at the ISI's World Statistics Conference in Japan in 2013.

well informed on developments and trends in the field of Statistics. Early on, what was available locally was limited. Also, since the Statistics group at Davis was young and small, our participating in conferences was a good way to give our program some visibility.

Editorial service involves some hard work, assessing the worthiness of a substantial number of submitted manuscripts (about 500 per year during my term as the T\&M Editor of the Journal of the American Statistical Association) and making some tough decisions about their publication. But the benefits to the evaluator far outweigh the burdens. The work exposes you to a wide spectrum of research ideas and, as a consequence, makes you a better researcher. George Duncan first invited me to join the $J A S A$ Editorial Board, and I'm grateful, to this day, for his extending that honor to me. I also served as an Associate Editor of JASA under Editors George Casella and Myles Hollander. I served as the Editor of the Theory and Methods Section of JASA in 2003-2005, after one year of service as Editor-Elect. I have always had great affection and respect for JASA. It is, in my view, the best Statistics journal in the world by virtue of the high quality of the papers it publishes and for being a journal which treats mathematical advances in Statistics with high regard but has the aspiration that its published papers contribute, as well, to real or potential statistical applications. I look back fondly on my years as Editor of JASA. While the acceptance rate was low (hovering around 20\%), I always made a point of offering some encouragement and constructive advice to the authors of papers that I was unable to accept. My intent was to provide some "value added" to all authors who submitted work to the journal.

I'll mention only briefly my editorial service to the journal Naval Research Logistics. I was drawn to the journal quite early in my career due to my interest in the area of Reliability Theory and the closely related field of Operations Research. In 1978, I published a paper in NRL on a model for open-bid auctions, and published some work on the treatment of "record-breaking" observations a few years later. I had some friendly and constructive correspondence with Editor Herbert Solomon during that time, and Herb ended up inviting me to serve as an Associate Editor. I held that post for some 30 years! I very much enjoyed it, both because of my interest in the journal's content and because of the collegiality of the editors I worked with.

\section{NONACADEMIC INTERESTS}

George: You have already elaborated extensively on your research interests, teaching, and your immediate family. Would you share with us some of your nonacademic interests?

Frank: I have long had an interest in art. This interest started when I was 16 years old and traveled in Europe with my family. When I started traveling professionally, I made a point of visiting galleries and museums that were near the conferences I attended, and I developed a real love and appreciation for painting and sculpture. I feel very fortunate to have enjoyed, up close and personal, the art of the Louvre, the Prado, the Uffizi and the Hermitage Museums (among many others), and I look forward to further opportunities to pursue that particular passion. When I retired as a Professor at UC Davis, I enrolled in a yearlong Docent Training course at the Crocker museum in Sacramento. It was a great experience, with lectures about art, field trips to nearby museums and regular interaction with a group of like-minded art enthusiasts. I have been a 
Docent at the Crocker Museum since 2014. I love giving tours at the Crocker and talking about art.

A secondary interest of mine is sports. The only sport I play now with some regularity is the game of paddle tennis. It is played with a tennis ball and wooden rackets. The game is played on a small court (about $20^{\prime}$ by $40^{\prime}$ ), which is why it appeals to older folks like myself. I had the concrete poured for such a court in my backyard about 30 years ago. I still enjoy playing! I also enjoy an occasional nine holes of golf.

\section{ADVICE TO YOUNG ACADEMICS, CONCLUDING REMARKS}

Debasis: After a long and successful academic career, what advice would you pass on to young faculty?

Frank: What I would stress in talking to young faculty about their careers is that balance between teaching and research is not only important for one's professional growth but provides value to the university, arming students with stimulating ideas and useful skills and advancing one's discipline, thereby expanding its potential utility and applicability.

There are challenges in an academic career that may not be easy to overcome. Think about what research entails. The term itself refers to the effort needed to discover something new. The very fact that one is dealing with the unknown, hoping to learn or notice something new, leaves open the possibility that one can fail. It has happened more than once that the solution to a problem is seen as difficult before the fact and is seen as trivial after the fact. That is why I have always described a dissertation problem as research in an area rather than research about a specific problem. My approach is to study a collection of problems, some of them taking shape as the research proceeds. One makes a judgement about what constitutes a doctoral dissertation sequentially, assessing the value of each discovery, and being finished when one is convinced that an "important" advance has taken place.

In the area of teaching, my experiences have been very positive. The positives start with the opportunity to specialize in something you love to think and talk about. Then there's the great pleasure of sharing what you love with others. At its best, it can lead to the satisfaction of having students choose to major in your discipline, and perhaps go on to study the field further in graduate school. Overall, I've been richly rewarded as a teacher, both through the interactions with my students while teaching them and by the satisfaction I have felt in seeing continued success in their subsequent education and in their careers.

One piece of advice that I would give young faculty is to get into the habit of applying for extramural support for their research. They will need to establish a track record of quality research early on, as this is often the key

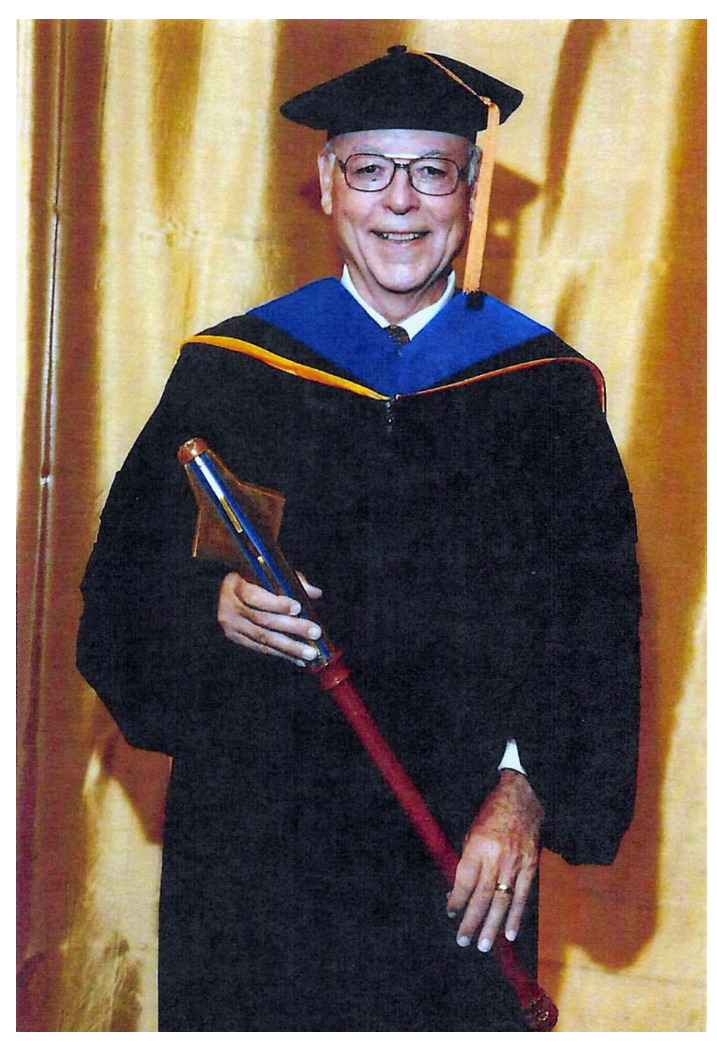

FIG. 8. Frank as Faculty Marshal at the 2016 Commencement of the College of Letters and Science at UC Davis.

to obtaining one's first research grant. Extramural support opens a plethora of doors, funding travel to conferences to present one's research findings and to see, first hand, what is new in your research specialties. Establishing contacts and relationships through conference participation will provide avenues for further professional interaction, something that can later play an important role in possible joint research and can also lead to opportunities for visits with researchers with common interests. The ability to offer financial support to promising graduate students is an effective way to expand the scope of one's own research program and increase its productivity, and has the equally important consequence of contributing to graduate students' understanding of what research is and what is involved in a successful research program. Extramural funding is especially helpful when supporting doctoral students who are writing their dissertations. The more time students can spend thinking about their research, the better are the results one can expect in the breadth and depth of their work.

George: Would you like to make some final remarks?

Frank: First, let me say that I am very grateful to you and Debasis for proposing this interview and for the time you've invested in doing it. It has given me the opportunity to reflect on key moments in my career and to express appreciation to people who had an influence on the paths I took. I owe a great deal to my teachers, to colleagues and staff members at Davis over my $40+$ year career and 
to my students, including the thousands I taught and the eight graduate students whose doctoral dissertations I directed.

My view of academic life is very positive. The balance between teaching and research is a major plus, as you can find substantial satisfaction in both, but you can also take comfort in one when the pleasure or satisfaction in the other has temporarily waned. Both can be intoxicating. The intense pleasure of the "aha" moment when working on a research problem is difficult to beat. But facilitating the "aha" moment in your students is equally exhilarating! Among the most appealing features of research in a university setting is the fact that you can work on problems that you personally consider interesting and of some importance. There are also rewards from working on problems that are brought to you, and I do have many fond memories of the challenging statistical projects that I worked on as a consultant, both within and outside of the university. Some of the most satisfying experiences in a research career can come from helping someone else solve a challenging problem. That said, it is a special pleasure to identify an interesting research problem and to succeed in developing a definitive solution.

George-Debasis: Thank you, Frank, for sharing your thoughts and reflections on your life and career.

Frank: Thank you both for the opportunity!

PS: All the works of Frank which have been referred to here and appeared in different journals are listed in [1].

SUPPLEMENTARY MATERIAL

Supplement to "A Conversation with Francisco J. Samaniego" (DOI: 10.1214/19-STS764SUPP; .doc). Supplementary information.

\section{REFERENCES}

[1] Roussas, G. G. and Bhattacharya, D. (2020). Supplement to "A Conversation with Francisco J. Samaniego." https://doi.org/10. 1214/19-STS764SUPP 